\title{
The Quest for Exciting Knowledge: Developments in Figurational Sociological Research on Sport and Leisure
}

\author{
Dominic MALCOLM \\ Loughborough University, United Kingdom \\ D.E.Malcolm@lboro.ac.uk \\ Louise MANSFIELD \\ Brunel University, United Kingdom \\ Louise.Mansfield@brunel.ac.uk
}

Recibido: 10-09-2012

Aceptado: 19-12-2012

\begin{abstract}
This paper provides a thematic and developmental review of figurational sociological research on sport and leisure. It demonstrates how Elias's main theoretical principles have been incorporated in this work and it uses ideas from Norbert Elias's sociology of knowledge to explain how the emphasis on these principles has changed over time. Specifically, the paper identifies three overlapping stages in the construction of this body of knowledge and argues that a focus on violence has gradually diminished. The paper argues that this trend is both a consequence of the increasing availability of a broader range of Elias's texts, but also due to social relations in the field, as latter generations of researchers find emotional gratification in expanding into new research agendas. The paper concludes by demonstrating the potential applicability of Elias's theoretical principles to some of the most significant social issues of the twenty first century.
\end{abstract}

Key words: figurational sociology, sport, leisure, Norbert Elias, sociology of knowledge

\section{Referencia normalizada}

Malcolm, D., Mansfield, D. (2013). The Quest for Exciting Knowledge: Developments in Figurational Sociological Research on Sport and Leisure”. Política y Sociedad, Vol.50 Núm 2: 397-419

Sumario: Introduction. 1.Norbert Elias: Key Sociological Principles. 2.The Emergence of a Figurational Sociology of Sport and Leisure. 3.The Establishment of a Figurational Sociology of Sport and Leisure. 4.Imminent Developments in the Figurational Sociology of Sport and Leisure: Health, Diaspora, Environment. 5. Conclusion. References. 


\section{Introduction}

Our aim in this paper is to illustrate how the key principles and ideas developed by Norbert Elias have been used in scholarship examining sport and leisure. This not only enables us to provide an explanation of the social significance of sport and leisure, but further to elucidate aspects of Elias's figurational or process sociological approach and make claims about its value as a tool for understanding the social world. This is, of course, not the first such attempt (see for example, Dunning, 1986; Murphy et al, 2000; Liston, 2011) for if there is one thing over which both critics of and collaborators with Elias agree, it is that he should be recognized as "highly unusual among leading sociologists" in seeing sport and leisure as important social phenomena (Giulianotti, 2004: 145. See also Jarvie and Maguire, 1994). Indeed it has been claimed that Elias not only saw sport and leisure as "constituting a problem area which merits investigation in its own right" but also as a "'natural laboratory' for shedding light on key aspects of human existence" (Dunning, 2002: 215).

We want, however, to attempt something rather different and more ambitious within this review. As Goudsblom (1977: 18) points out, while "It is customary to write the history of sociology in terms of individual contributors", this approach is fundamentally flawed because "No matter which [individual] name is chosen there is something arbitrary and misleading about the choice". The difference between those people and texts which are highlighted and those which are excluded is often just "a matter of degree" (Goudsblom, 1977: 21). Consequently we want to structure this review in two distinctly Eliasian ways. First, we seek to provide an account which is both thematic and fundamentally developmental. Second, we want to structure our observations and account for the developmental trajectories we illuminate within an Eliasian framework of the sociology of knowledge. In this sense, we want to produce a sociology of figurational sociological research on sport and leisure, and to advance this argument through the kind of radical interplay of theory and evidence which Elias advocated.

\section{Norbert Elias: Key Sociological Principles}

We cannot, within the limits of this article, present a detailed overview of Elias's entire sociological project and indeed this task has been done well elsewhere (Loyal and Quilley, 2004; Mennell, 1992; Van Krieken, 1998). However, an overview of the key principles of Elias's ideas is central in our endeavour to examine the significance of his work to sport and leisure scholarship. Elias's primary concern for sociology was to build more adequate funds of knowledge; knowledge which survives "reality testing ... in the crucible of experience" (Elias, 1987: 56). Such knowledge would be a necessary precondition, though alone insufficient, for the improvement of the human condition. For Elias this was the purpose and promise of scholarship. While the epistemological position Elias advocated took Weber's value 
neutrality as a point of departure, he did not constrain his thinking with a commitment to an abstract and static philosophical notion of 'truth'. Rather, through "a passionate commitment to sociology" (Kilminster, 2004: 34), Elias strove to contribute to the development of forms of thinking that would enable human understanding of natural forces and social relations to develop increasing predictability. Elias's notion of understanding and potentially improving human life was, therefore, characteristically Eliasian; concerned with the process rather than an end point, conscious always that the portrayal of human constructs as static entities constituted a fundamental misrepresentation of social life.

Elias's most well known, and arguably most significant book is The Civilising Process - voted seventh in the International Sociological Association's "Most Influential Books of the Twentieth Century" - and as Liston rightly observes (2011: 161), The Civilising Process "has become synonymous with Elias's figurational sociology". However, Elias's contribution to sociology is more extensive than the influence of a single book when one considers his work as a series of conceptual arguments that interweave and represent a comprehensive theory of human society. With an emphasis on breaking the divide between theory and evidence, Elias developed his theoretical framework as he engaged in his sociological research. Thus, the theoretical and conceptual discussions that suffuse The Civilising Process come to the fore, develop and are refined in different ways in other works such as The Society of Individuals (1991), The Court Society (1983), The Established and the Outsiders (1994), The Germans (1996), Mozart: Portrait of a Genius (1993), Involvement and Detachment (1987), The Symbol Theory (1991), and What is Sociology? (1978). Elias's thinking extended to the social construction of: identity (particularly, but not solely, in relation to established and outsider groups); science as a social institution; time as a means of human orientation; and the process of death and dying. Sport was also important, for while The Civilising Process explored the relationship between social development (sociogenesis) and developments in personality structures (psychogenesis) primarily in relation to France and Germany, "Elias's work on sport ... constituted his main attempt to contribute to the understanding of English social development” (Dunning, 1992: 98). While The Civilising Process, and indeed much of the figurational research on sport and leisure, has been viewed through a substantive focus on violence and its social control, a more nuanced view is that Elias undertook an "analysis of the historical development of emotions and psychological life ... in relation to the connections ... with larger scale processes such as state formation, urbanisation and economic development” (van Krieken, 1998: 353).

If we concern ourselves with the theoretical underpinnings rather than the empirical focus we can see that Elias's sociological approach involves at least five overlapping principles: (1) human societies can only be understood in terms of long-term processes of change; (2) human life is characterised by interdependent relations which are diverse and shifting and underpinned by ever-changing balances of power; (3) human societies are characterized by different degrees of, and a dynamic interplay between, internal and external social controls, with the increasing 
internalisation of the latter in relatively complex societies; (4) human acts involve processes in which intentional action contributes to unintended or unplanned patterns of relationships; (5) social life is characterised by balances and blends of emotional involvement in and detachment from the contexts in which human beings find themselves.

It is our contention that the figurational sociological analysis of sport and leisure has developed in line with a growing awareness of the variety and multiplicity of Elias's texts, and thus also a more rounded appreciation of his theoretical approach. We should not, of course, underestimate the significance of The Civilising Process, and indeed the focus on violence, within a figurational framework (particularly as it relates to sport). Though couched as no more than a working hypothesis, Elias saw The Civilising Process as his "central theory" (Liston, 2011) and he was no doubt attracted to the study of sport both because it constituted an area in social life in which apparently high degrees of violence were relatively tolerated, and because it seemed to be a significant medium through which the English defined themselves as "civilized" and thus distinct from others. However, our task here is to expand our understanding of developmental trends in the production of figurational research on sport and leisure using key principles of Elias's sociology of knowledge. That is to say, we reject the idea that academic researchers are closed, discrete entities (or homo clauses) and stress, like Elias, a sociological approach which conceives of humans as open and necessarily social beings (or homines aperti). Moreover, our approach is premised on the belief that there is a significant interrelationship between particular social conditions and particular ways of thinking and acting; and that knowledge cannot be divorced from its social and processual character.

More specifically, we wish to argue that a strong singular commitment to Elias's ideas about violence and violence control in The Civilising Process is no longer experienced as the main trajectory of conceptual thinking by those figurational sociologists of sport and leisure whose knowledge production post-dates earlier work in this 'tradition'. Rather as has been suggested (Mennell, 1992; Mansfield, 2008; Malcolm, 2011), the 'usefulness' of knowledge will be shaped by the ability of a group to justify their view of the world to other humans, as well as the sense of emotional gratification knowledge generates for its holders. In making sense of the social world of sport and leisure, more recent theoretical-empirical work shows a passion for different, diverse and more nuanced applications of Elias's work. There is arguably evidence amongst this generation of Eliasian researchers of a reinvolvement with feelings of pleasure and excitement associated with the discovery of different ways of using his work. As Kilminster (2004: 35) puts it, sociologists experience "pleasure and excitement in relation to activities such as discovery in which they are habitually applying a standard of detachment and an orientation to factual research". For him this is a type of "secondary reinvolvement”, a pleasure associated with the potential for knowledge that comes with a comprehensive understanding of theoretical-empirical case studies (Kilminster, 2004: 33-4). Yet it is the very potential of Elias's sociological principles to making sense of the 
complexities of sport and leisure in social life which, for us, explains the enduring and diverse set of commitments to harnessing his work. Thus contemporary figurational sociologists of sport do not deny the validity of Elias's work on violence, but find greater emotional and intellectual gratification in research which advances other principles of Eliasian sociology. There are, therefore, social scientific and social reasons for the trends in sport and leisure research conducted by figurational sociologists.

In the following sections we focus on three stages in the construction of figurational sociological sport and leisure knowledge. In the emergent phase we detail studies of the long-term development of modern sport which expanded our understanding through the application of theoretical ideas which are particularly explicit in Elias's The Civilising Process. In the second phase, in which figurational sociological research becomes more established in the subdiscipline, we see a relative decline in violence-oriented empirical work and, through analyses of globalization, health, pain and injury, and gender the development of a more sustained focus on the five overlapping principles identified above. Finally we discuss an imminent phase of research, identifying developing areas of empirical exploration such as health, diaspora and environment. We conclude by arguing one of the consequences of the breadth of Elias's sociological project was the development of an extensive range of theoretical tools which have continuing relevance within a radically revised social research context. We present these three stages alongside a warning about the dangers of 'process reduction'. As will be seen, these stages are not discrete entities. We see always the seeds of subsequent developments scattered in the fertile soil of preceding phases.

\section{The Emergence of a Figurational Sociology of Sport and Leisure}

The emergence of a figurational sociology of sport and leisure was fundamentally structured by the key empirical themes of The Civilising Process. This can be seen in relation to three bodies of work: Elias's own writings on sport and leisure; Dunning and Sheard's Barbarians, Gentlemen and Players (1979); and the 'Leicester School' of football hooliganism research.

With the exception of Elias's first excursus into sport, an article called "The Dynamics of sports groups with special reference to football” (Elias and Dunning, 1966), which essentially promoted Elias's concept of figuration through a critique of micro-sociology or "small group theory", all the early sport-related works were structured by concerns related to violence and its social control. In the initial essay "Quest for excitement in leisure", Elias and Dunning (1969) suggest that the social significance of sport in contemporary societies is directly related to, and fundamentally interdependent with, broader social changes affecting the control of violence, bodily habits and emotional expression. Two years later, in an anthology edited by Eric Dunning, Elias (1971) contributed a chapter on sport in Ancient Greece and a co-authored chapter on folk football in medieval Britain (Elias and 
Dunning, 1971). In the former Elias addresses an apparent refutation of his argument in "Quest for excitement"; namely the common perception that the sports of Ancient Greece represent something of the pinnacle of civilized sporting achievement and thus that, by comparison, contemporary sports are "less" civilised. He does this by: a) charting the relatively violent nature of sport in Ancient Greece which had relatively informal rules and were structured according to a warrior ethos (as opposed to the modern sporting ethos of "fair play"); and b) contextualising this with the relatively violent tenor of social life in Ancient Greece. In the latter, Elias and Dunning delineated the relatively violent characteristics which distinguished folk football from its modern counterpart. Thirdly, in what constitutes Elias's "major statement on sport and leisure" (Giulianotti, 2004: 146), the co-authored book, Quest for Excitement (Elias and Dunning, 1986), Elias (1986) illustrates the relationship between parliamentarization and the emergence of modern sport in eighteenth century England through an analysis of the development of fox hunting, as well as two works which Elias saw as significant contributions towards his sociology of the emotions: a restatement of the thesis of the "quest for excitement", and the analysis of sport as part of a broader "spare-time spectrum" (first published in 1971). ${ }^{1}$

At this point Elias's engagement with sport began to wane, no doubt influenced by his emigration from the UK which meant that he was no longer in close daily contact with his colleague Eric Dunning (Waddington and Malcolm, 2008). However, the legacy of his early work and ideas continued, as can most clearly be demonstrated in Dunning and Sheard's Barbarians, Gentlemen and Players (1979). Empirically Barbarians explores the development of association and rugby football, providing a theoretical framework for the understanding of how modern sport came to take its contemporary form. Whilst addressing the development of the British class structure (and particularly the role of the public schools) and the trend towards increasing seriousness and competitiveness in sport as well as its increasing centrality in contemporary culture, of greater theoretical significance is the argument that the development of rugby football entailed a "civilising spurt" in two key senses. First, standards of violence control advanced in that the exercise of stricter and more even self-control was demanded of players (e.g. the introduction of referees, rule-making bodies and the abolition of some relatively violent practices) and second, proponents of football attempted to distinguish themselves from the rugby "up starts" on the basis of the levels of violence and self-control exhibited in their respective games.

Barbarians concluded with a brief discussion of football hooliganism and this subject would come to dominate the work of figurational sociologists of sport

\footnotetext{
${ }^{1}$ Elias also started to write a paper on the relationship between boxing and duelling in England and France. While multiple versions of this paper remain, he never finished the piece and so it remains unpublished.
} 
throughout the 1980s. The prominence of football hooliganism as a social issue at this time was a key factor in the development of the study of sport as a reputable sociological sub-discipline but, more than this, it provided an important (and particularly pertinent) vehicle for the application of Elias's theoretical ideas to sport and leisure. The so-called "Leicester School" emerged as the dominant perspective on football hooliganism (Giulianotti, 1999). The main premises of the approach drew on Elias and Dunning's (1969) "Quest for Excitement" in highlighting the generation of particular forms of excitement as a central motivating force for the (mainly) young men involved, and linked to Elias's The Civilizing Process in arguing that the socialization experiences in the working class communities from which the majority of hooligans stemmed tended to generate a habitus which was relatively tolerant of violence and aggression (Dunning et al., 1988). The work was characterized by a commitment to contextualise contemporary manifestations of football hooliganism with reference to its historical development.

While clearly structured around a violence-orientated agenda, the emergence of a figurational sociology of sport and leisure though these three bodies of work also illustrates the five overlapping principles discussed in the introduction. Each of the above bodies of work exhibited an approach which was fundamentally developmental, entailing analyses which spanned at least 100 years or more. Each stressed interdependency (e.g. in terms of sportization being structured by the emergence of parliamentary democracy, between different social classes in the development of football and rugby), the balance between internal and external controls (the pacification of hunting, the rule-bound nature of modern sport, the experiences of hooligans), the significance of unintended as well as intended consequences of human action (the escalating effect of police attempts to control hooliganism) and the blend of involvement and detachment. ${ }^{2}$

\section{The Establishment of a Figurational Sociology of Sport and Leisure}

While the figurational sociological analysis of sport and leisure could never have been described as "mainstream", it was around the late 1980s that critiques of the approach became most marked. The developmental orientation of this body of research brought figurational sociologists into conflict with sports historians, some of whom disputed the veracity of their empirical findings, and others who questioned the benefits of sociology's commitment to theoretically driven research more generally (Mason 1988; Holt 1989). The research also drew criticism from a

\footnotetext{
2 The dominance of the 'Leicester School' was not simply academic, but related also to political influence. Consequently this body of research included a specifically policyoriented dimension and thus is illustrative of the importance of the Eliasian concept of 'secondary re-involvement'.
} 
growing community of feminist sociologists of sport due to the empirical focus on males and male sport, and the correlative exclusion of females and female sporting experiences (Hargreaves, 1992). But most significantly and most consistently, criticisms of the figurational sociological analysis of sport and leisure focused on the prominence of violence (Curtis, 1986; Stokvis, 1992). It was in response to these critiques that the figurational sociological research on sport and leisure was shaped.

Some of these research themes (e.g. globalization and health, pain and injury) were responses to developments in the broader sociological research agenda whilst others (e.g. gender) can be seen as relatively direct developments of critiques of Elias's perspective. Each bears the influence of Elias's theory of civilising processes but each, in their own way, also shows a concern to present figurational sociology as a theoretical perspective able to deliver knowledge which was socially useful in the crucible of experience.

\subsection{Sport and Globalization}

As Waters (1995: 1) suggested, "globalization may be [or may have been] the concept of the 1990s" and for over 3 decades, Joseph Maguire has consistently and convincingly advocated drawing out key ideas from Elias's The Civilising Process to understand the changing nature of sport in relation to globalization. Identifying the significance of long-term processes of global change Maguire argues that social life develops in relation to struggles between members of interdependent nation states and that such "inter-civilizational encounters" are characteristic of the global character of modern sport (Maguire, 1999: 38). By this analysis, the structures and practices of global sport result from a historical interweaving of societies and individuals; through centuries of international relations. Such relationships are marked by a "mutual contest of cultural sameness, difference and commingling between competing groups" resulting in a complex global sports landscape of intended action and unintended consequences (Maguire, 1999: 64-65). Long-term sportization processes underpinning the global development of regulated, competitive, masculinised, performance sport are entwined with state formation and the growth of national communities, an emphasis on individual achievement, and the development and domination of science. Such developments are in turn consistent with Elias's demonstration of the increasing prominence of rationality and forethought as part of the European civilizing process.

The emergence and diffusion of global sport then, for Maguire, illustrates Elias's ideas about civilising processes that explain how, over time, and through complex struggles, Western societies came to dominate as relatively established groups within a European context succeeded in diffusing Western forms of (civilising) conduct and taste to outsider groups. The diffusion of a particular conception of sport as well as individual sport forms characterised this process and the diffusion of cricket in particular provides one of the most complete examples. Cricket was 
originally "invented" in England and while its global diffusion has subsequently been relatively limited to the extent that it is little understood across,continental Europe, it became an "umbilical cord of Empire linking the mother country with her children” (Mangan, 1986: 153). But the game was not simply a popular expression of taste in such diverse territories, it formed the basis of a code of moral behaviour which included the curbing of emotional expression and the impropriety of challenging authority. As clearly illustrated in CLR James' Beyond a Boundary (1963), even as subaltern populations sought to reject the exploitative political relations of imperialism to which they were subject, a remarkably uncritical perspective towards the game and its principles has endured. This aspect of globalisation, therefore, clearly demonstrates how the long term development of interdependency ties exhibit blends of emotional involvement and detachment, and the dynamic interplay of external and internal social controls or habitus.

In the contemporary world the extent of international sport development as well as success on an international stage is bound up with a series of global contests played out in terms of human resources (as athletes, and for talent identification, coaching and training), good governance of sports organizations (for finance management and facility/equipment provision) and the influence and accessibility of sports science and medicine. Global sport networks are also marked by a hierarchy of established-outsider sporting nations in which some are more able than others to secure status through international sport success and concomitantly influence the overall shape and trajectory of the global sports arena in relation to capital, technology, media imagery, ideology (particularly in relation to body cultures and identification) and labour migration. Thus, Maguire's (1999) final analysis highlights that from the late twentieth century, in the realm of sport performance success, the organisation and control of international competition and development, and sporting status it is the West that provides the dominating force. So too do Western nations take the lead and the prestige in relation to the production and marketing of sports goods and services. Yet, the dominance of Western cultural interchange has never been secured and negotiation, resistance and rejection are always evident in the global sports figuration. Maguire (1999: 93) concludes that, in relation to sport and leisure, "Globalization can therefore be understood in terms of the attempts by more established groups to control and regulate access to global flows and also in terms of how indigenous peoples both resist these processes and recycle their own cultural products”.

\subsection{Health, Injury and Medicine}

A second sport and leisure research theme to which figurational sociologists have significantly contributed is the analysis of health, injury and medicine. Young (2004) is undoubtedly right to locate the development of this genre of research in relation to the discipline-wide development of a sociology of the body - or better, an embodied approach to sociology. Moreover, it is pertinent to add that these 
developments, in and of themselves, contributed to the demonstration of the broader currency of figurational sociological ideas, with Elias featuring prominently in the work of leading "body scholars" such as Shilling (1993) and Featherstone (1991) which shaped this emerging area of scholarship. Significantly, however, both developments were marked by a utilization of Elias's ideas which, whilst linked to The Civilising Process, move beyond a relatively narrow focus on violence and draws upon a more expansive conceptual tool kit.

The figurational sociological analysis of health and medicine has deep roots (Waddington, 1984; de Swaan, 1988). In relation to sport, while Waddington and Murphy's (1992) analysis attributing (in part) the increasing use of performanceenhancing drugs to a broader, society wide, process of medicalization may represent the beginning, a perhaps more significant development was Waddington's critique of the relationship between sport and health (Waddington, 2000; Waddington and Murphy, 1998; Waddington, Malcolm and Green, 1998). Waddington et al. sought to "debunk" the myth (Elias, 1978) that sports participation inevitably led to health benefits by examining the different kinds of social relations entailed in different kinds of physical activity. Thus, Waddington et al. argued, while there is compelling evidence that moderate, rhythmic and gentle exercise had health benefits, when exercise involves more complex interdependencies - e.g. with an opponent, team mates, as a full time or paid professional, as an international representative - the prominence of unintended outcomes (e.g. injury and health averse practices such as supplement/drug use) becomes considerable.

There followed a series of research projects which examined athletes' experiences of injury in professional football (Roderick et al., 2000), rugby union (Malcolm and Sheard, 2002), rowing (Maguire and Pike, 2003) and amongst student athletes (Liston et al., 2006). These studies laid bare the impact of the social relations which remained largely hypothesized in Waddington et al.'s earlier work. Empirical examples were provided which illustrated the direct and indirect effect of players' relations with coaching and medical staff, of the enabling and constraining effects of these relations on athletes' decisions to train and compete while injured or in pain. The internalisation of external constraints on social behaviour was illustrated in athlete's widespread acceptance of the legitimacy of ideologies which prioritized short-term sporting performance over longer-term health concerns. The prominence of the unintended outcomes of purposeful human action were illustrated by evidence which confirmed the existence of a "risk-pain-injury paradox" (Nixon, 1993); namely that in their determination to be successful in sport, athletes showed a propensity to act in ways which were likely to lead to more frequent injury and therefore ultimately reduce their overall chances of achieving their primary goal (sporting success).

A commitment to the study of human interdependencies logically led to a more clinician-focussed body of research (Waddington, 1996). Waddington and Roderick (2002) showed how the social relations specific to sport figurations constrained doctors' attempts to conform to professional guidelines about the maintenance of patient/athlete confidentiality. The tensions in working relations between doctors 
and physiotherapists were discussed by Malcolm (2006), while Malcolm and Scott (2011) explored aspects of both intra- and inter-professional relations amongst doctors and physiotherapists working in multidisciplinary sports medicine teams. A significant culmination of this work has been the analysis of the blend of emotional involvement and detachment in decision making in relation to health and illness in sport. Malcolm (2011) has argued that the relative occupational insecurity of being an elite athlete leads to the generation of a habitus which is likely to be highly egocentric and inclined towards making relatively involved or emotional decisions regarding sports participation. Furthermore, clinicians whose extensive occupational training inculcates a relatively "rational", scientific or "detached" habitus, find their action-inclinations challenged by the specific interdependencies of sport figurations. At the extreme, the influence of the immediate relations in these figurations is such that clinicians may come to reject their profession's knowledge in favour of lay understandings of medical conditions.

In concluding this section, two final points need to be made. First, despite an early theoretical intervention into this field which called for an emphasis on understanding longer-term developments in attitudes towards pain and injury in sport (Roderick, 1998), such studies have not been forthcoming (Sheard, 2006 is an exception). While this must be recognized as an omission, it should be stressed that process remains an important conceptual point for figurational researchers in this area. In particular the importance of socialisation processes (Roderick et al., 2000), and the impact of commercialisation (Malcolm and Sheard, 2002) and professionalization (Scott, 2010; Malcolm and Scott, 2011), have been concerned to locate developments in personality structure within a broader context of social structural development. Second, while the empirical focus on pain and injury perhaps lends itself to a return to violence and Elias's theory of civilising processes, it is interesting to remark on how rarely this connection is explicitly made in this body of work.

\subsection{Sport, Leisure and Gender}

In the face of a corpus of critical literature in the sociology of sport which claimed that figurational sociological work was relatively silent about and limited in answering questions on gender (Hargreaves, 1992, 1994; Horne and Jary, 1987), figurational sociologists have made significant contributions to advancing sport and gender relations. Initially this work tended to focus on male sports culture (see for example Dunning, 1986; Dunning et al. 1988; Maguire, 1986; Sheard and Dunning, 1973) and its significance to understanding the gendered character of sport was not necessarily recognised until "gender relations" - as opposed to "women and sport" was accepted as the proper focus of feminist study of sport (Birrell, 1988: 481). Subsequently, however, empirical studies of the experiences of women and theoretical debates about the potential of blending feminist principles with those of Norbert Elias have emerged to answer questions about gender and sport (Colwell, 
1999; Dunning and Maguire 1996; Liston, 2006, 2007; 2008; Maguire and Mansfield, 1998; Mansfield, 2002; 2008; Velija, 2012). Reflecting on Dunning and Maguire's (1996) discussions about the significance of Elias in understanding sport, gender relations and violence control, Mansfield $(1998,2002)$ argued that thinking with feminist sensibilities about female subjectivity and experience at the same time as harnessing Elias's foundational principles of civilising processes could advance understandings of female involvement in sport. Framed by on-going intellectual exchanges between feminists and figurational sociologists, researchers have more recently used Elias's ideas to consider sport and gender in terms of: (1) the relative empowerment of females in the male preserve of sport; (2) the motivations, meaning and significance of sport and exercise for women; and (3) the impact of women's involvement on the formation and reformation of their sense of self identity.

Mansfield's exploration of the overall structure of fitness cultures and the relations between the organisation of fitness practices, images/messages of fitness and the formation and reformation of femininities presents theoretical-empirical work founded on involved-detachment; a feminist interpretation of Elias's position on "involvement-detachment". In her words

Involved-detachment is a balance signalling a feminist passion or motivation to investigate gender relations in sport from an inside perspective; a requirement to be involved, but recognizing and examining the feminist assumptions of the research endeavour and working towards an appropriate degree of detachment from those feminist values in the advancement of knowledge about gender, sport and sportrelated activities (Mansfield, 2008: 105).

These arguments reflect Elias's position that greater degrees of, and standards for, self-control as well as an intensifying capacity for greater self-reflection, characterise civilising processes in all areas of social life including intellectual work significant in the growth of human knowledge upon which political action and social change might be possible. On understanding women's experiences of fitness, Mansfield also argues for scholarship on gender that is historically located and embraces a time perspective which is capable of considering long-term processes of change as they are interlinked with more medium and short-term relationships in social life.

\section{Imminent Developments in the Figurational Sociology of Sport and Leisure: Health, Diaspora, Environment}

In the previous two sections we have sought to demonstrate how research into sport and sport-related phenomena by figurational sociologists has developed over time. Fundamentally this review showed a tendency in more recent times to eschew the relatively direct influence of The Civilising Process and focus on and elaborate Elias's broader toolkit of concepts. In this final section we wish to illustrate our anticipation that this developmental trend will continue. In particular, through a 
focus on what we consider to be three of the most prominent social concerns of our time - both in relation to sport and more broadly - we seek to argue that a theoretical engagement with Elias's ideas has the potential to continue to provide sociologists with the ability to produce more advanced socially useful knowledge. The first of these is in relation to health.

Health is one of the most salient and contested dimensions of human societies. Concepts of health and illness are central to the meanings that people attach to life and death, and perceptions of health tend to reflect competing moral views about "good/healthy" and "bad/un-healthy" lifestyles (Shilling 1993; Turner 2000). Knowledge, understanding and experiences of health differ between and within groups of people and are shaped by specific socio-cultural contexts and biopsychological conditions. Health is a corporeal problem of control. Underpinning issues of bodily control are questions about the relationship between external regulation of individual and collective bodies and internalized self-control of behaviour and emotion; a central concern in Elias's work. A key tenet of his conceptualisation of social life and a principle that emerges in his sociological language is of human beings "in the round" constituting a dynamic blend of biopsychological and socio-cultural characters rather than a miscellany of disembodied functions, actions and emotions. At times Elias's work focuses quite intimately on the way that human beings live in and through their bodies. As he traces the history of manners and personality in The Civilising Process and the character of behaviour in The Court Society for example, he identifies changes in the expectations that people have of themselves and others in their interpersonal relations, some of which were rooted in health and hygiene. Since the Middle Ages such changes have been marked by more evident processes of social constraint over appearance, behaviour and expressions of emotion, increasing attention to hygienic bodily rituals, and concomitantly more firmly self-regulated bodies. The emergence of more sophisticated codes of etiquette surrounding what some people should and should not look like and what people could and could not do with their bodies was intertwined with perceptions of some human behaviours as increasingly repugnant. For Elias, the tendency in long-term processes of change is for social control to become deeply internalized (embodied) and operate at both conscious and unconscious levels as processes of self-constraint.

In debates about population trends towards increasing body weight and expanding rates of obesity, and associated health consequences, arguments about fat people lacking individual self control and discipline are common place, inadequate and discriminatory. Equally simplistic is the promotion of sport and physical activity as the panacea to problems of overweight and obesity. Elias's ideas may help to advance our understandings of bodies and health because in the case of overweight, fat and obesity, individual behaviour is shaped by interdependent relationships with other human beings in a variety of contexts of which sport and physical activity may be one. The nature and character of bodily self-control is, then, a consequence of social-individual dynamics and cannot be defined simply as a personality trait or as something for which individuals can be praised or blamed 
(Stuiz, 2011). Following Stuiz (2011), Elias's framework for understanding embodiment places individual action, say to participate in physical activity or reflect upon nutritional intake, in social context at the same time as recognising the dynamics of historical and socio-cultural processes. Trends in body weight and the associated health consequences differ over time, as do trends in sport/physical activity participation, but crucially also they differ between and within groups of people in different social positions in any society. There is a "differential acquisition of new forms of self-control" in response to changing social environments (Stuiz, 2011: 809). Contemporary bodily regulation towards thinness for example can be associated with middle class and celebrity values conflating lean bodies with health, beauty and desire and feeding an anti-fat ethic; a cultural distaste for fat which appears to be reinforced in sport and leisure cultures (Mansfield, 2010). Elias's conceptualisation of the socio-dynamics of stigmatization in exploring the ways that fat people are blamed for a lack of self control, the gossip and taboos that surround narratives about fat, emotional constructions of fear and loathing of fat, and the mobilization of personal and social mechanisms that stigmatize those who are fat (Mansfield, 2010) has considerable potential. In contemporary Western cultures fat is an exemplar of the complex interface of personal-political issues framing health policy, health services and health practise. Elias's accounts of social-individual dynamics and the significance of anxiety as an emotional driver in human relations may, thus, provide a means of understanding and furthering knowledge specifically in the current obesity debate and more broadly in discussions about health matters in human populations.

A second major challenge of the $21^{\text {st }}$ century is to some extent an extrapolation of the globalization trends discussed earlier, but relates specifically to the movement of people. Initially analysed under the umbrella of "race" and "migration", a major recent development has been the emergence of "diaspora studies". While initially diaspora was a descriptive term used in human geography to refer to displaced or dislocated communities which had moved (often forcibly) from their "native homeland", increasingly it has been used to reflect the impact of both the local and the global on peoples' conceptions of self; their "mutliplicity of belongings and identities" (Kalra et al. 2005: 16). The notion of diaspora has only recently been used in relation to a critical sociology of sport (see, e.g. Burdsey, 2006; Carrington, 2010), but we are struck by how the main themes of diaspora resonate with the key ideas of Elias's sociology. Like Elias's work, diaspora is inspired by multidisciplinarity. Like Elias's sociological theory, the concept of diaspora focuses on the importance of fluidity or process. Diaspora is premised not simply on the assumption that geographies, nationalities and ethnicities are socially constructed, but that construction of identity is fundamentally an outcome of interdependent relations marked by complex power relations. It has been pointed out variously by scholars in sport and the wider field of sociology that to make sense of the ways people define themselves and others, and the processes by which people give meaning to themselves and others, must incorporate proper consideration of power relations that turn difference into systems of inequality and 
subordination (Brah, 1991; Carrington, 2010; Sugden and Tomlinson, 2002). Important too is analysis of identification at many intersecting levels of difference and sameness (Elias, 1998; Mennell, 1992).

Following Elias (1978, p. 118), theorising about identity requires one to think of people in constant motion; being in "process" rather than simply going "through a process" The argument that self-images and we-images are always constructed and reconstructed over time, at different levels, in specific geographical locations and within groups of interdependent people provides a basis for conceptualising identity as always multi-layered. Sport and leisure provide various settings for the making of an array of identities some of which are shared by people and some which reflect difference and diversity. Burdsey's (2006) discussion of British-Asian males' engagement with football is an example, for which they may play in ethnically homogeneous teams they also express a commitment to the (male) England national team.

The precise characteristics of identification will vary according to the manner and extent to which socio-cultural factors are interwoven into a person's habitus (Mennell, 1994). Habitus refers to the feelings and modes of behaviour and tastes that predominate among group members and can also be thought of in terms of "second nature", reflecting the deeply ingrained, subconscious character of habitus. The concepts of habitus and identity are closely related. Identity can be differentiated from habitus because it represents a more conscious awareness, a degree of reflective articulation, and some emotional account of the shared characteristics of a group, as well as an understanding of those traits that are perceived as different from other people (Elias, 2000; Mennell, 1994). People's propensity to play particular sports is a component of habitus and participation is an expression of identity.

It therefore seems to us that Elias's central principles are particularly pertinent to these most recent developments in the sociology of race. The context or figuration specific nature of power and identity, and the conceptualization of these as mutually conditioning processes (Mennell, 1994) is a central tenet of Elias's theoretical framework. Taking the sporting experiences of the black Caribbean diaspora in Britain as an example, we can see how a multiplicity of identifications (e.g. with the West Indian "national" cricket team, with the local neighbourhoods currently inhabited, and with a game - cricket - defined as uniting the British Empire) enable and constrain an "outsider" group in their struggle against exclusion and discrimination (Malcolm, forthcoming). An ability to understand and play cricket facilitates cross-ethnic relations and provides a sense of selfhood which is central to legitimating identities. Yet it also serves as a source of tension as members of this diasporic group are seen to play the game in a way which is defined as "alien" by the established, "host" community and thus contributes to the placement of these identities within a status hierarchy. The precise expression of such power struggles and the making and re-making of the self varies according to the social conditions under examination (Mennell, 1994, p. 185). Figurational sociologists of sport and leisure are therefore already grappling with the theoretical principles underlying the 
concept of diaspora and this suggests the continuing relevance of Elias as new social issues and research agendas arise.

We would contend, for our third case study, that concerns about the impact of human beings on the environment in which they live represents one of the most dominant discourses in popular culture and the academic community in the $21^{\mathrm{st}}$ century. The ubiquitous global environmental problems of inter alia climate change, waste management, energy consumption, pollution and biodiversity have fostered the emergence and formalisation of green politics, the legitimation of green activism and an increasing sensitivity to ecological problems in daily life. It has been noted in the sport and leisure literature that there has been an increasing awareness of the potential environmental problems engendered by the continuing unmanaged growth of sport, leisure and tourism (Mansfield, 2009, Mansfield and Wheaton, 2011). Mansfield and Wheaton's (2011) collection of papers on leisure and the politics of the environment illustrate a set of wide ranging cross-cultural debates within the field as well as the significance of exploring conceptual frameworks from other disciplines such as geography, the environmental sciences and sociology in advancing knowledge about sport, leisure and ecological issues. This type of interdisciplinary synthesis in understanding the complex interactions of humans and their environment represents the focus of some of the most recent scholarship that advocates Elias's way of thinking about sustainable development. We argue that sport and leisure researchers may find such work of significance in advancing knowledge about the character and impact of sporting practices on the environment in which they take place.

Integrating the historical and social sciences with an understanding of biological perspectives frames de Vries and Goudsblom's (2003) approach to mapping out the long-term, dynamic and evolutionary processes which characterise the co-existence of humanity and its environment. Their work is intimately tied to an Eliasian framework as it seeks to provide a dynamic world-view about human social life and the habitats in which human beings have found themselves around the globe for many millennia. There is (again) an emphasis here on the fluid and shifting pattern of social and ecological relationships in an account of the environment that recognises the significance of repeated processes in nature (such as the rising and setting of the sun and ebb and flow of tides) as they interweave with more spontaneous natural occurrences (like volcanic eruptions and earthquakes) and are intertwined with the intensive impacts of human processes on the landscape and climate. The conceptualisation of the anthroposphere is at the core of de Vries and Goudbslom's (2003) long-term socio-ecological account of humans and their habitats as well as being a key tenet of the work of other scholars using Elias's ideas to further understanding of the ecology of human life (see for example, Quilley, 2004; 2011). The anthroposphere represents the overall human presence and set of activities in the Earth's system and includes the built environment, culture and technology that structures human life on the earth, in it and beyond it. We would argue that a sensitivity to the broad range of perspectives about the anthroposhere; an interdisciplinary perspective, may well be of use in studies of 
human beings and their sporting endeavours. Exploring the dynamics and complexities of human/human and human/non-human relationships in the anthropospheric context of sport would include attention to the nature and character of the built sport environment as well as the culture and technologies of sport over time. Understanding the co-existence of sporting features of humanity with the environment (in the anthroposphere and at the intersection of the anthroposhere and the overall biosphere) may well have positive consequences for sustainable development. On the one hand, as Quilley (2004: 54) points out, one of the consequences of human development is the Promethean quest for "ecological expansion and domination". But on the other hand, and at the same time, "it is possible that the species with the greatest capacity for destabilizing impacts on nonhuman nature may yet prove to be the only species capable of exercising evolutionary self-restraint - the semi-political and semi-conscious internalization of restraints in relation to nature and the environment" (Quilley, 2004: 54). While a long-term, interdisciplinary, socio-ecological perspective does not guarantee a knowledge platform for appropriate human action to engage in and develop sport in a sustainable way, we would advocate it as a perspective for advancing knowledge about the complexities of human/non-human interdependencies and as a way for understanding which sport and leisure practices get developed where, how and in whose interests (Mansfield, 2009).

\section{Conclusion}

Our aim in constructing this review of figurational sociological research on sport and leisure has been to convey something of the process of knowledge development. Inevitably it is not possible to cover everything that is relevant. Although we have compartmentalised a broader process into three stages, we wish to again stress the overlapping, contingent nature of each. Indeed we see the study of gender straddling the first and second phases (and undoubtedly also the third) and work on health and sport straddling the second and third. Important and influential research into sport and violence is still undertaken by figurational sociologists of sport (Malcolm, 2002; Sanchez and Malcolm 2010). Thus it would be wholly wrong to assume that figurational sociologists have rejected concepts used more prominently in earlier phases simply because their prominence has diminished. Here, a return to Elias's guidance to think in terms of blends, balances or degrees is useful.

Often reviews such as this are conducted in an asocial and static manner with major disjunctures between different bodies of work, and new areas arising with seeming autonomy; simply the "logic" that certain knowledge gains are so compelling that the resolution of particular problems at particular times is inevitable. We have no doubt that amongst all the professional groups in society, academics are relatively self-determining, relatively free to pursue avenues which they consider to be socially important, and concerned to defend their intellectual independence. But Elias also teaches us that knowledge and social structure are 
highly interdependent, that humans are enabled and constrained by historical and social interdependency ties. Any account of the development of figurational sociological scholarship should, therefore, embrace this point.

Thus in our view, the emergence of a figurational sociology of sport and leisure was inextricably linked to the relatively small corpus of Elias's works available at that time. Elias's central theory, elaborated in The Civilising Process, was both highly applicable to sport, and able to be elaborated upon through sport. But over time the "use value" of this synergy began to wane in the sense that the conventions of social science dictated that knowledge was tested and developed through critique and competing interpretations. While continually - and to our minds convincingly rebutted an additional strategy was to shift the research agenda. Researchers may have moved away from the study of violence because they were constrained by other figurational sociologist (e.g. the depth with which hooliganism had been studied by Dunning et al. meant that significantly adding to figurational knowledge of this phenomenon was particularly challenging) and enabled by the expanding corpus of Elias's works and ideas. Subsequent generations of researchers were likely to experience greater emotional satisfaction from a) not having to repeatedly defend The Civilising Process and a focus on violence from its critics; and b) the sense of doing something new and the pleasure and excitement that knowledge discoveries entailed.

To take from this, however, that the production of academic knowledge is entirely free-floating and an entirely opportunist and subjective process would be a mistake. While Elias emphasises that the construction of knowledge is a social process, he illustrated that knowledge changes on the basis of its perceived use value. Part of this use value is emotional gratification. The "usefulness" of Elias's sociology in the knowledge produced by figurational sociologists of sport and leisure is very much shaped by the ability of those researchers to justify their view of the world to others. The applicability of Elias's ideas to such a diverse body of empirical subjects, to such cutting edge themes and social concerns, makes the continued commitment to this approach incredibly exciting and likely to endure in the longer term. While Mennell (1989: 191) is right to note that "knowledge is always knowledge for practical purposes, and can always be thrown into doubt as new problems arise”, we also concur with Waddington and Smith (2009: 8) who recognise that "there is nothing as practical as good theory". 


\section{References}

Birrell, S. (1988): "Discourses on the Gender/Sport Relationship: From Women in Sport to Gender Relations”, in Exercise and Sport Science Reviews, 16: 459-502.

Burdsey, D. (2006): “'If I Ever Play Football, Dad, Can I Play for England or India?' British Asians, Sport and Diasporic National Identities”, Sociology, 40, 1: 11-28.

Brah, A. (1991): "Questions of Difference and International Feminism”, in Aaron, J. and Walby, S. (eds.), Out of the margins: Women's studies in the Nineties, London, Routledge, 168-176.

Carrington, B. (2010): Race, Sport and Politics: The Sporting Black Diaspora, London, Sage.

Colwell, S. (1999): "Feminisms and Figurational Sociology: Contributions to Understandings of Sports, Physical Education and Sex/Gender", European Physical Education Review, 5, 3: 219-40.

Curtis, J. (1986): "Isn't it Difficult to Support Some of the Notions of 'The Civilising Process'? A Response to Dunning”, in Rees, C.R. and Miracle, A. (eds) Sport and Social Theory, Champaign, Il.: Human Kinetics, 57-65.

De Swaan, A. (1988): In Care of the State, Oxford, Oxford University Press.

De Vries, B. and goudsblom, J. (2003): Mappae Mundi: Humans and their Habits in a Long-term Socio-Ecological Perspective. Myths, Maps and Models. Amsterdam, Amsterdam University Press.

Dunning, E. (1986): "The Sociology of Sport in Europe and the United States: Critical Observations From an 'Eliasian' perspective”, in Rees, C.R. and Miracle, A.W. (eds) Sport and Social Theory, Champaign, Il.: Human Kinetics, 29-56.

Dunning, E. (1992): “A Remembrance of Norbert Elias”, in Sociology of Sport Journal, 9: 95-99.

Dunning, E. (2002): "Figurational Contributions to the Sociological Study of Sport", in Maguire, J. and Young, K. (eds.) Theory, Sport and Society, Oxford, Elsevier Science, 211-238.

Dunning, E. and Maguire, J (1996): "Aspects of Sport, Violence and Gender Relations: Some Process-Sociological Notes", in International Review for the Sociology of Sport, 31, 295-322,

Dunning, E., Murphy, P. and Williams, J. (1988): The Roots of Football Hooliganism: An Historical and Sociological Study, London, Routledge, Kegan, Paul.

Dunning, E. and Sheard, K. (1979): Barbarians, Gentlemen and Players: A Sociological Study of the Development of Rugby Football. Oxford, Martin Robertson.

Elias, N (1971): “The Genesis of Sport as a Sociological Problem”, in Dunning, E. (ed) The Sociology of Sport: A Selection of Readings, London, Frank Cass, 88115.

Elias, N. (1978): What is sociology? London, Hutchison.

Elias, N. (1983): The Court Society, Oxford, Blackwell. 
Elias, N. (1986): “An Essay on Sport and Violence”, in Elias, N. and Dunning, E. Quest for Excitement: Sport and Leisure in the Civilising Process, Blackwell: Oxford, 150-174.

Elias, N. (1987): Involvement and Detachment, Oxford, Blackwell.

Elias, N. (1991): The Society of Individuals, Oxford, Blackwell.

Elias, N. (1991): The Symbol Theory, London, Sage.

Elias, N. (1993): Mozart: Portrait of a Genius, Cambridge, Polity Press.

Elias, N. (1994): The Established and the Outsiders, London, Sage, $2^{\text {nd }}$ edition

Elias, N. (1996): The Germans, Cambridge, Polity Press.

Elias, N. (1998): On Civilization Power and Knowledge: Selected Writings. Chicago, University of Chicago Press.

Elias, N (2000): The Civilising Process (revised edition). Oxford, Blackwell.

Elias, N. and Dunning, E. (1966) "Dynamics of Sports Groups with Special Reference to Football”, in British Journal of Sociology, XVII, 4: 388-402.

Elias, N. and Dunning, E. (1969): “The Quest for Excitement in Leisure”, in Society and Leisure, 2: 50-85.

Elias, N. and Dunning, E. (1971): "Folk football in Medieval and Early Modern Britain", in Dunning, E. The Sociology of Sport: A Selection of Readings, London, Frank Cass, 116-132

Elias, N. and Dunning, E. (1986): Quest for Excitement: Sport and Leisure in the Civilising Process, Blackwell, Oxford.

Featherstone, M. (1991): “The Body in Consumer Culture”, in Featherstone, M., Hepworth, M. and Turner, B.S. (eds) The Body: Social Process and Cultural Theory, London, Sage, 170-196.

Giulianotti, R. (1999): Football: A Sociology of the Global Game, Cambridge, Polity.

Giulianotti, R. (2004): "Civilizing Games: Norbert Elias and the Sociology of Sport”, in Giulianotti, R. (ed) Sport and Modern Social Theorists, Basingstoke, Palgrave Macmillan, 145-160.

Goudsblom, J. (1977): Sociology in the Balance: A Critical Essay, Oxford, Blackwell.

Hargreaves, J.A (1992): 'Sex, Gender and the Body in Sport and Leisure: Has There Been a Civilizing Process?”, in Dunning, E. and Rojek, C. (eds) Sport and Leisure in the Civilizing Process: Critique and Counter-critique, Basingstoke: Macmillan, 161-182.

Hargreaves, J.A. (1994): Sporting Females: Critical Issues in the History and Sociology of Women's Sports, London, Routledge.

Holt, R. (1989): Sport and the British, Oxford, Oxford University Press.

Horne, J., and Jary, D. (1987): "The Figurational Sociology of Sport and Leisure of

Elias and Dunning: An exposition and Critique”, In Horne, J., Jary, D. and Tomlinson, A. (Eds.), Sport, Leisure and Social Relations, London, Routledge \& Kegan Paul, 86-112.

James, C.L.R. (1963): Beyond a Boundary, London, Hutchison. 
Jarvie, G. and Maguire, J. (1994): Sport, Leisure and Social Thought: London, Routledge.

Kalra, V., Kahlon, R.K. and Hutnyk, J. (2005): Hybridity and Diaspora, London, Sage

Kilminster, R. (2004): "From Distance to Detachment: Knowledge and SelfKnowledge in Elias's Theory of Involvement and Detachment”, in Loyal S. and Quilley, S. (Eds.), The Sociology of Norbert Elias, Cambridge, Cambridge University Press, 25-41.

Liston, K. (2006): "Women's Soccer in the Republic of Ireland: Some Preliminary Sociological Comments”, in Sport in Society, 7, 2/3: 364-84.

Liston, K. (2007): "Revisiting the Feminist-Figurational Sociology Exchange', in Sport in Society, 10, 4: 623-645.

Liston, K, (2008): "The Problem of Ideology in Making Sense of Physical Education and Sport: Reflections on the Colwell-Mansfield Debate”, in European Physical Education Review, 14, 1: 123-33.

Liston, K. (2011): "Sport and Leisure”, in The Sociological Review, 59: 260-180

Liston, K., Reacher, D., Smith, A., and Waddington, I. (2006): "Managing Pain and Injury in Non-Elite Rugby Union and Rugby League: A Case Study of Players at a British University", in Sport in Society, 9: 388-402.

Loyal, S. and Quilley. S. (2004): The Sociology of Norbert Elias, Cambridge, Cambridge University Press.

Maguire, J. (1986): "Images of Manliness and Competing Ways of Living in Late Victorian and Edwardian Britain”, in British Journal of Sports History, 3, 3:265287.

Maguire, J. (1999): Global Sport: Identities, Societies, Civilizations, Cambridge, Polity.

Maguire, J. and Mansfield, L. (1998): "No-body's Perfect: Women, Aerobics and the Body Beautiful”, in Sociology of Sport Journal, 15, 2: 109-37.

Maguire, J. and Pike, E. (2003): "Injury in Women's Sport: Classifying Key Elements of 'Risk Encounters'", in Sociology of Sport Journal, 20, 3: 232-251

Malcolm, D. (2002). "Cricket and Civilizing Processes: A Response to Stokvis”, in International Review for the Sociology of Sport, 37, 1: 37-57.

Malcolm, D. (2006): "Unprofessional Practice? The Status and Power of Sports Physicians", in Sociology of Sport Journal, 23: 376-395.

Malcolm, D. (2011): "Sports Medicine, Injured Athletes and Norbert Elias's Sociology of Knowledge”, in Sociology of Sport Journal, 28: 284-302.

Malcolm, D. (2013): Globalizing Cricket: Englishness, Empire, Identities, London, Bloomsbury Academic.

Malcolm, D. and Scott, A. (2011): "Professional Relations in Sport Healthcare: Workplace Responses to Organisational change”, Social Science and Medicine, 72: 513-520.

Malcolm, D., and Sheard, K. (2002): “Pain in the assets': The Effects of Commercialization and Professionalization on the Management of Injury in English Rugby Union”, in Sociology of Sport Journal, 19: 149-169. 
Mangan, J.A. (1986): The Games Ethic and Imperialism: Aspects of the Diffusion of an Ideal, London: Frank Cass.

Mansfield, L. (2002). "Feminist Thought and Figurational (Process) Sociology”, in J. Maguire and K. Young (Eds.), Theory, Sport and Society. London: JAI Elsevier Science, 317-35.

Mansfield, L. (2008): "Reconsidering Feminisms and the Work of Norbert Elias for Understanding Gender, Sport and Sport-related Activities", in European Physical Education Review, 14, 1: 93-121.

Mansfield, L. (2009): “Fitness cultures and environmental (in) justice?” International Review for the Sociology of Sport, 44, 4: 345-362

Mansfield, L. (2010). "Fit, Fat and Feminine: the Stigmatisation of Fat Women in Fitness Gyms', in Kennedy, E. and Markula, P. (Eds.) Women and exercise: Qualitative research on the body, health and consumerism. London: Routledge. 81-101.

Mansfield, L., and WHEATON, B. (2011): "Leisure and the politics of the environment: Editorial Introduction”, Leisure Studies 29, 3: 349-351.

Mason, A. (1988): Sport in Britain, London, Faber and Faber.

Mennell, S. (1992): Norbert Elias: An Introduction, Blackwell, Oxford.

Mennell, S. (1994): "The Formation of We-Images: A Process Theory", in C. Calhoun (ed.) Social Theory and the Politics of Identity.Oxford, Blackwell. 175198.

Murphy, P., Sheard, K., and Waddington, I. (2000): "Figurational Sociology and its Application to Sport", in Coakley, J. and Dunning, E. (Eds.), Handbook of Sports Studies, London, Sage, 92-105.

Nixon, H. L. II (1993): “Accepting the Risks of Pain and Injury in Sport: Mediated Cultural Influences on Playing Hurt” in Sociology of Sport Journal, 10: 183-196.

Quilley, S. (2004): “Ecology, 'Human Nature' and Civilizing Processes: Biology and Sociology in the Work of Norbert Elias", in S Loyal and S. Quilley (Eds.): The Sociology of Norbert Elias, Cambridge: Cambridge University Press, 42-59.

Quilley, S. (2011): "Entropy, the Anthroposphere and the Ecology of Civilization: an Essay on the Problem of 'Liberalism in one Village' in the Long View", The Sociological Review, 59, 65-90.

Roderick, M. (1998): "The Sociology of Risk, Pain and Injury: A Comment on the Work of Howard L. Nixon II", in Sociology of Sport Journal, 15: 64-79.

Roderick, M., Waddington, I., and Parker, G. (2000): "Playing Hurt: Managing Injuries in English professional Football", in International Review for the Sociology of Sport, 35: 165-180.

Sanchez Garcia, R. and Malcolm, D. (2010). "De-civilizing, Civilizing or Informalizing? The International Development of Mixed Martial Arts", in International Review of the Sociology of Sport, 45, 1: 1-20.

Scott, A. (2010): “More Professional?" The Occupational Practices of Sports Medicine Clinicians Working with British Olympic Athletes. Unpublished $\mathrm{PhD}$ thesis, Loughborough University, UK. 
Sheard, K and Dunning, E (1973): 'The Rugby Club as a Type of Male Preserve: Some Sociological Notes', in International Review of Sport Sociology, 8: 5-24.

Sheard, K. (2006): "Pain and Injury in Boxing: The Medical Profession Divided", in Loland, S., Skirstad, B. and Waddington, I. (Eds.) Pain and Injury in Sport:

Social and Ethical Analysis, London, Routledge, 127-143.

Shilling, C. (1993): The Body and Social Theory, London, Sage.

Sugden, J. and Tomlinson, A. (2002). Power games: A critical sociology of sport. London: Routledge.

Stokvis, R. (1992): “Sport and Civilization: is Violence the Central Problem?” in Dunning, E. and Rojek, C. (1992) Sport and Leisure in the Civilizing Process, London, Macmillan, 121-136.

Stuiz, M. (2011). "Explaining Trends in Body Weight: Offers Rational and Myopic Choice vs Elias' Theory of Civilising Processes", in Social History of Medicine, 243, 796-812.

Turner, B. (2000): The Body and Society. London, Sage.

Van Krieken, R. (1998): Norbert Elias, London, Routledge.

Velija, P. (2012): “Nice Girls Don't' Play Cricket: The Theory of Established and Outisder Relations and Perceptions of Sexuality and Class Amongst Female Cricketers, in Sport in Society, 15, 1. 28-43.

Waddington, I. (1984): The Medical Profession in the Industrial Revolution, Dublin, Gill \& Macmillan.

Waddington, I. (1996): “The Development of Sports Medicine”, in Sociology of Sport Journal, 13, 176-196.

Waddington, I. (2000): Sport, Health and Drugs: A Critical Sociological Perspective, London, E\&F Spon.

Waddington, I. and Malcolm, D. (2008): “Eric Dunning: This Sporting Life”, in Malcolm, D. and Waddington, I. (Eds.) Matters of Sport: Essays in Honour of Eric Dunning, London, Routledge, 1-11.

Waddington, I., Malcolm, D. and green, K. (1998): "Sport, Health and Physical Education”, in European Physical Education Review, 3, 2: 165-182

Waddington, I and Murphy, P. (1992) "Drugs, Sport and Ideologies", in Dunning, E. and Rojek, C. (Eds.) Sport and Leisure in the Civilizing Process: Critique and Counter-critique, Basingstoke, Macmillan, 36-64.

Waddington, I. and Murphy, P. (1998): "Sport for All: Some Public Health Policy Issues and Problems”, in Critical Public Health, 8, 3: 193-205.

Waddington, I. and Roderick, M. (2002): "The Management of Medical Confidentiality in English Professional Football Clubs: Some Ethical Problems and Issues”, in British Journal of Sports Medicine, 36: 118-123.

Waddington, I. and Smith, A. (2009): An Introduction to Drugs in Sport: Addicted to Winning? London, Routledge.

Waters, M. (1995): Globalization, London, Routledge.

Young, K. (2004): 'Sports-related Pain and Injury: Sociological Notes', in Young, K. (ed) (2004) Sporting Bodies Damaged Selves: Sociological Studies of Sports Related Injuries, Oxford: Elsevier Press, 1-28. 